\title{
Interactive role of diabetes mellitus and female sex in the risk of cholangiocarcinoma: A population-based nested case-control study
}

\author{
Yan-Jiun Huang ${ }^{1,2}$, Alexander TH Wu², Hung-Yi Chiou ${ }^{5}$, Ming-Tsang Chuang ${ }^{5}$, \\ Tzu-Ching Meng ${ }^{6}$, Li-Nien Chien ${ }^{4, *}$, Yun Yen ${ }^{2,3, *}$ \\ ${ }^{1}$ Department of Surgery, Division of Colorectal Surgery, Taipei Medical University Hospital, Taipei, Taiwan \\ ${ }^{2}$ The Ph.D. Program for Translational Medicine, Taipei Medical University \& Academia Sinica, Taipei, Taiwan \\ ${ }^{3}$ Graduate Institute of Cancer Biology and Drug Discovery, College of Medical Science and Technology, Taipei Medical \\ University, Taipei, Taiwan \\ ${ }^{4}$ School of Health Care Administration, College of Management, Taipei Medical University, Taipei, Taiwan \\ ${ }^{5}$ School of Public Health, College of Public Health and Nutrition, Taipei Medical University, Taipei, Taiwan \\ ${ }^{6}$ Institute of Biological Chemistry, Academia Sinica, Taipei, Taiwan \\ *These authors have contributed equally to this work \\ Correspondence to: Yun Yen, email: yyen@tmu.edu.tw \\ Li-Nien Chien, email: Inchien@tmu.edu.tw \\ Keywords: cholangiocarcinoma, diabetes, population-based, intrahepatic, extrahepatic
}

Received: October 26, $2016 \quad$ Accepted: November 30, $2016 \quad$ Published: December 27, 2016

\section{ABSTRACT}

Diabetes mellitus (DM) has been associated with an increased risk of extrahepatic cholangiocarcinoma (ECC) and intrahepatic cholangiocarcinoma (ICC). However, the role of DM in a population with a lower incidence of ECC remains unclear. We investigated the role of DM and other risk factors for ECC and ICC by conducting a population-based, nested, case-control study in Taiwan, a region with a lower incidence but a higher proportion of ICC. We identified patients who received a diagnosis of cholangiocarcinoma (CC) from the Taiwan Cancer Registry between 2003 and 2009. A total of 6,093 CC cases (ICC: 4,695; ECC: 1,396) and 60,906 matched controls were included. Compared with the controls, the patients with ICC and ECC were more likely to have DM, with an adjusted OR of 1.22 [95\% confidence interval (CI): 1.07-1.39] and 1.48 (95\% CI: 1.18-1.85), respectively. DM was associated with an increased risk of $\mathrm{CC}$ in the women and patients without a history of biliary tract diseases. Moreover, compared with the controls, DM was not associated with an increased risk of ECC in the patients who received cholecystectomy. These findings strongly support the positive association between DM and the increased risk of both ICC and ECC; however, this association was not observed in the patients who received cholecystectomy.

\section{INTRODUCTION}

Cholangiocarcinoma (CC) is primarily a cancer of the epithelial cells (mostly adenocarcinoma) in the bile ducts arising anywhere along the intrahepatic or extrahepatic biliary tree $[1,2]$. CC accounts for approximately $3 \%$ of all gastrointestinal cancers [3, 4]. The incidence rate of $\mathrm{CC}$ is high in Asia including Thailand and Korea [5]. In Western countries, extrahepatic $\mathrm{CC}(\mathrm{ECC})$ is the most common type, with $6 \%-8 \%$ of CCs being intrahepatic CC (ICC) and $27 \%-42 \%$ being ECC [1, 2]; this pattern in Western countries is different from that observed in East Asia [5].

Several epidemiological studies have reported that risk factors for ECC and ICC and the heterogeneity concept associated with ECC and ICC are different [5-8]. Numerous biliary tract diseases have been identified as risk factors for $\mathrm{CC}$, including primary sclerosing cholangitis, liver flukes (Opisthorchis viverrini and Clonorchis sinensis) found in endemic regions such as Thailand, 
cholelithiasis, hepatolithiasis [3-5], and congenital biliary tract abnormalities such as choledochal cysts $[3,6,7,9]$. Among these risk factors, pancreaticobiliary maljunction, cholelithiasis, and cholecystectomy have been associated with ECC [5]. By contrast, hepatitis B virus (HBV), hepatitis $\mathrm{C}$ virus (HCV), hepatolithiasis, and cirrhosis have been associated with ICC [5]. In addition, a study suggested that diabetes mellitus (DM) is associated with an increase in CC in Western countries [10]. However, its role in Asian countries remains controversial because of heterogeneity in the study design, selected study population, and study regions [11-16].

CC typically has a poor prognosis, with a 5-year survival rate of $11 \%-44 \%$ even after curative surgery [17]. Moreover, although $\mathrm{CC}$ is a rare malignancy in Western countries, it is more common in Asia. Because of an increasing prevalence of DM in Asia [18-19], understanding the role of DM in patients with ICC and ECC can be beneficial. In addition, identifying crucial risk factors for $\mathrm{CC}$ can help physicians in providing valuable preventive therapeutic strategies. Therefore, this study investigated the interactive role of DM in patients with ICC and ECC by performing a population-based, nested, case-control study.

\section{RESULTS}

\section{Study sample}

The initial cohort consisted of over 8,000,000 NHI beneficiaries, and the final cohort consisted of 6,093 CC cases (ICC: 4,695; ECC: 1,396) and 60,906 age- and sexmatched controls (Figure 1).

\section{Basic characteristics}

Table 1 lists the demographics, disease diagnoses, and medication use of the patients with ICC and ECC and their matched controls. The mean age of the patients with ICC and ECC was 67.8 (SD: 11.2) and 70.6 (SD: 11.4) years, respectively. The percentage of men was higher among the patients with ECC than among the patients with ICC (59.1\% vs. 52.1\%). Compared with the controls, both the patients with ICC and ECC were more likely to have $\mathrm{DM}$, biliary tract diseases, cirrhosis, chronic pancreatitis, peptic ulcer, and $\mathrm{CCI}>3$ and receive $H$. pylori eradication therapy. Moreover, compared with the controls, the patients with ICC were more likely to have alcoholic liver disease, $\mathrm{HBV}$, and $\mathrm{HCV}$, whereas the patients with $\mathrm{ECC}$ were more likely to receive PPIs and NSAIDs.

\section{Diabetes and risk factors for ICC and ECC}

Figure 2 presents risk factors for ICC and ECC. Compared with the controls, the patients with ICC and ECC were more likely to be exposed to DM, with an adjusted OR of 1.22 (95\% CI: 1.07-1.39) and 1.48 (95\%
CI: 1.18-1.85), respectively. Biliary tract diseases and cirrhosis were also more likely to occur in the patients with ICC and ECC. However, compared with the matched controls, the higher odds of alcoholic liver disease, HBV, and peptic ulcer were observed only among the patients with ICC.

\section{Stratified analysis}

Figure 3 presents the adjusted odds of DM among different subgroups. The risk of DM was associated with ICC and ECC among the women, with an adjusted OR of 1.42 (95\% CI: $1.17-1.71)$ and 1.82 (95\% CI: 1.31-2.54), but not in the men. Compared with the controls, the risk of DM was more positively associated with ICC and ECC in the patients without biliary tract diseases. However, DM was not found to be associated with the risk of ECC in the patients who received cholecystectomy.

\section{DISCUSSION}

The results of this study revealed that compared with the age- and sex-matched controls, both the patients with ICC and ECC were more likely to have DM after adjustment for all potential risk factors. In addition, in the subgroup analysis, the risk of DM was associated with ICC and ECC in the women but not in the men. Compared with the controls, the risk of DM was more positively associated with ICC and ECC in the patients without biliary tract diseases. However, DM was not found to be associated with the risk of ECC in the patients who received cholecystectomy.

The strength of this study is that it effectively explored differences in the association of risk factors for ICC and ECC with DM by using a nationwide, large sample-sized, and homogeneous populationbased cohort. This approach prevents the selection and recall biases observed in previous case-control studies [11-15]. In addition, other strengths of this study are as follows. First, disease conditions, medications, and treatments were obtained from a single-payer insurance system with a comprehensive coverage. Second, multiple regression analyses were performed to adjust all potential confounding biases that can be observed in this cohort. The progress in the understanding of ICC has been limited by its rarity in Western countries. The ratio of ICC to ECC observed in our national cohort was quite different from that observed in Western countries. Although the ratio of the number of the patients with ICC $(\mathrm{N}=4695)$ to the number of the patients with ECC $(\mathrm{N}=1398)$ is high in our national cohort, unexplained rising incidence of ICC has been reported in studies conducted in Europe and the United States in recent years [7, 16, 17].

In general, the percentage of men was higher among the patients with ECC than among the patients with ICC (59.1\% vs. 52.1\%). Moreover, the mean age of the patients with ICC was higher than that of the patients with ECC. 
Our study results revealed that compared with the controls, the patients with ECC were more likely to receive PPIs and NSAIDs. The association between longterm PPI use and carcinoma has remained questionable for years. A recent study reported an association of the long-term use of PPI with the risk of periampullary cancers [18]. Furthermore, studies have postulated that carcinoma is secondary to hypergastrinemia because of its use for over 15 years [18-19]. On the basis of these findings, two mechanisms underlying the association of ECC carcinogenesis with the use of PPI have been proposed. First, strong acid suppression causes an increase in serum gastrin levels. Prolonged and increased gastrin can stimulate an increase in intermediates that have trophic effects on the normal gastrointestinal mucosa, resulting in the stimulation of carcinogenesis. Second, Bernstein et al. suggested that bile acids act as carcinogens in human gastrointestinal cancers [20]. A long-term exposure to bile acids activates prosurvival stress-response pathways and affects several genes or proteins associated with chromosome maintenance and mitosis [22]. Therefore, a likely mechanism through which hydrophobic bile acids induce ECC is the bile acid induction of reactive oxygen species, reactive nitrogen species, and DNA damage in the cells of the gastrointestinal tract. If the stress induced by chronic inflammation is very high, it can also affect cellular defenses, resulting in cell death [22].

Biliary tract diseases including cholelithiasis and cholangitis are risk factors for both ICC and ECC. Patients with cholangitis or cholelithiasis have at least a 4-fold increase in the risk of $\mathrm{CC}[3,6]$. Gallstones induce biliary inflammation, and cholecystectomy is typically followed by the dilation of bile ducts, which might also cause inflammation and thereby possibly increase the risk of CC [23]. Although gallstone disease is common, only approximately $1 \%$ of patients with gallstones develop biliary tract cancer, implying that other factors may be involved in the pathogenesis of the cancer [24-25]. We particularly focused on IHC in this study because of the recent identification of a rising disease incidence in line with the rising number of DM cases in Asia. Previous studies on the association between DM and CC have yielded conflicting results $[7,11-13]$. Our results demonstrated and confirmed that the risk of DM was positively correlated with ICC and ECC. Among our patients with ICC and $\mathrm{ECC}$, the risk of diabetes was higher in the women with an adjusted OR of 1.42 (95\% CI: 1.17-1.71) and 1.82 (95\% CI: 1.31-2.54), respectively. Moreover, the patients with ICC were more likely to have diabetes, biliary tract diseases, and cirrhosis and receive $H$. pylori eradication therapy and metformin. The analysis of the SEER-

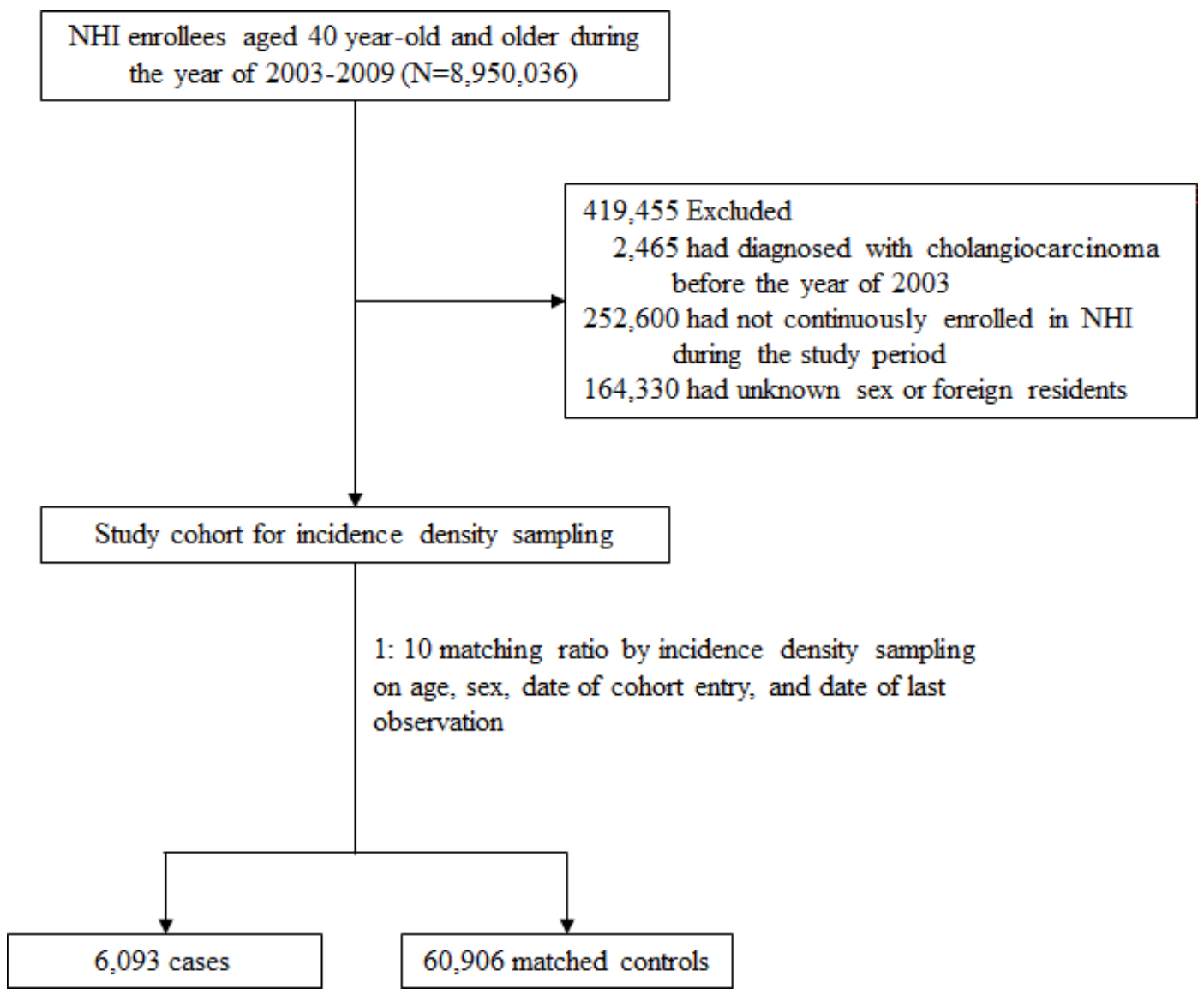

Figure 1: Flow Chart of the Selection Process of Cases and Matched Controls. 
Table 1: Characteristics of cholangiocarcinoma cases and matched controls

\begin{tabular}{|c|c|c|c|c|c|c|}
\hline & ICC & $\begin{array}{l}\text { Matched } \\
\text { Controls }\end{array}$ & & ECC & $\begin{array}{l}\text { Matched } \\
\text { Controls }\end{array}$ & \\
\hline & $\mathbf{N}(\%)$ & $\mathbf{N}(\%)$ & $\boldsymbol{P}$ & $\mathbf{N}(\%)$ & $\mathbf{N}(\%)$ & $\boldsymbol{P}$ \\
\hline Total & $4,695(100)$ & $46,942(100)$ & & $1,398(100)$ & $13,964(100)$ & \\
\hline Male & $2,448(52.1)$ & $24,480(52.1)$ & & $826(59.1)$ & $8,252(59.1)$ & \\
\hline $\operatorname{Age}(\mathrm{yr})$, mean(SD) & $67.7(11.2)$ & $67.8(11.3)$ & & $70.6(11.4)$ & $70.7(11.4)$ & \\
\hline \multicolumn{7}{|c|}{ Previous or coexisting medical condition } \\
\hline Diabetes & $978(20.8)$ & $8,353(17.8)$ & $* *$ & $309(22.1)$ & $2,573(18.4)$ & ** \\
\hline Biliary tract diseases & $619(13.2)$ & $749(1.6)$ & $* *$ & $195(13.9)$ & $279(2.0)$ & $* *$ \\
\hline Hemochromatosis & $3(0.1)$ & $22(0.0)$ & & $3(0.2)$ & $11(0.1)$ & \\
\hline Cirrhosis & $191(4.1)$ & $636(1.4)$ & $* *$ & $33(2.4)$ & $173(1.2)$ & $* *$ \\
\hline Alcoholic liver disease & $35(0.7)$ & $155(0.3)$ & $* *$ & $8(0.6)$ & $47(0.3)$ & \\
\hline $\begin{array}{l}\text { Chronic non-alcoholic liver } \\
\text { disease }\end{array}$ & $25(0.5)$ & $172(0.4)$ & & $7(0.5)$ & $42(0.3)$ & \\
\hline $\mathrm{HBV}$ & $138(2.9)$ & $513(1.1)$ & $* *$ & $23(1.6)$ & $164(1.2)$ & \\
\hline $\mathrm{HCV}$ & $112(2.4)$ & $541(1.2)$ & $* *$ & $24(1.7)$ & $172(1.2)$ & \\
\hline Chronic pancreatitis & $9(0.2)$ & $24(0.1)$ & $* *$ & $4(0.3)$ & $12(0.1)$ & $*$ \\
\hline Inflammatory bowel disease & $22(0.5)$ & $192(0.4)$ & & $8(0.6)$ & $52(0.4)$ & \\
\hline Peptic ulcer & $955(20.3)$ & $8,102(17.3)$ & $* *$ & $323(23.1)$ & $2,717(19.5)$ & $* *$ \\
\hline GERD & $114(2.4)$ & $1,015(2.2)$ & & $31(2.2)$ & $334(2.4)$ & \\
\hline Cardiovascular disease & $892(19.0)$ & $8,947(19.1)$ & & $307(22.0)$ & $3,092(22.1)$ & \\
\hline Hyperlipidemia & $611(13.0)$ & $7,003(14.9)$ & $* *$ & $209(14.9)$ & $2,086(14.9)$ & \\
\hline \multicolumn{7}{|c|}{ Charlson comorbidity index, mean(SD) } \\
\hline 0 & $2,079(44.3)$ & $25,579(54.5)$ & $* *$ & $583(41.7)$ & $6,877(49.2)$ & $* *$ \\
\hline 1 & $1,097(23.4)$ & $10,221(21.8)$ & & $352(25.2)$ & $3,291(23.6)$ & \\
\hline 2 & $736(15.7)$ & $5,370(11.4)$ & & 211(15.1) & $1,770(12.7)$ & \\
\hline$\geq 3$ & $783(16.7)$ & $5,772(12.3)$ & & $252(18.0)$ & $2,026(14.5)$ & \\
\hline \multicolumn{7}{|l|}{ Medication } \\
\hline H. pylori eradication therapy & $620(13.2)$ & $5,311(11.3)$ & $* *$ & $287(20.5)$ & $1,875(13.4)$ & $* *$ \\
\hline PPIs & $281(6.0)$ & $2,635(5.6)$ & & $92(6.6)$ & $792(5.7)$ & * \\
\hline $\mathrm{H}_{2} \mathrm{RA}$ & $121(2.6)$ & $1,139(2.4)$ & & $44(3.1)$ & $386(2.8)$ & \\
\hline Aspirin & $954(20.3)$ & $9,977(21.3)$ & & $344(24.6)$ & $3,447(24.7)$ & \\
\hline NSAIDs & $997(21.2)$ & $9,826(20.9)$ & & $365(26.1)$ & $3,284(23.5)$ & $*$ \\
\hline Statins & $307(6.5)$ & $3,491(7.4)$ & $*$ & $95(6.8)$ & $1,103(7.9)$ & \\
\hline Metformin & $565(12.0)$ & $4,893(10.4)$ & $* *$ & 161(11.5) & $1,472(10.5)$ & \\
\hline Insulins & $104(2.2)$ & $820(1.7)$ & $*$ & $35(2.5)$ & $278(2.0)$ & \\
\hline Other antidiabetic drug & $710(15.1)$ & $6,036(12.9)$ & $* *$ & $210(15.0)$ & $1,904(13.6)$ & \\
\hline
\end{tabular}

Abbreviation: ICC, intrahepatic cholangiocarcinoma; ECC, extrahepatic cholangiocarcinoma; biliary tract diseases: choledochal cysts, cholangitis, cholelithiasis and cholecystitis; HBV, hepatitis B virus; HCV, hepatitis C virus; GERD, gastroesophageal reflux disease; PPIs, proton pump inhibitors; $\mathrm{H}_{2} \mathrm{RA}$, histamine-2 receptor antagonists; NSAIDs, non-steroid anti-inflammatory drugs.

$* P<0.05, * * P<0.001, P$ value was based on the unadjusted regression analysis. 
Medicare databases indicated that DM was at least 2.5-fold more common in the patients with ICC than in the patients undergoing resection of hepatic colorectal metastasis, supporting the suggestion of the etiological role of DM [7].

Because DM is a public health issue worldwide, is most noticeable disease in developing countries, and has an increasing prevalence in the Asia Pacific, identifying the most susceptible population and protecting them from exposure to risks can be helpful [26]. In Taiwan, DM is a major health issue with an estimated 900,000 patients with DM among its 23 million local inhabitants. The annual incidence of DM has reached $0.5 \%-1 \%$ of Taiwan's total population, suggesting that there are at least 100,000 new cases every year. In addition, there has been a sharp rise in the prevalence of diabetes among Taiwanese citizens aged 65 years and older (from $8.7 \%$ in 1989 to $15.1 \%$ in 1999), as reported by the Taiwanese Department of Health [27]. Our data analysis demonstrated that compared with the controls, both the patients with ICC and ECC were more likely to have DM. Two Surveillance, Epidemiology and End Result (SEER) studies have also reported a positive association between diabetes and CC. In addition, Grainge et al. conducted a large, population-based, casecontrol study in the United Kingdom and demonstrated an association between diabetes and CC. After controlling for other risk factors in the stratified analysis of the risk of DM, we observed that DM itself was more pronounced in the nonbiliary tract disease group and also more significantly associated with bile duct cancer in the women than in the men. Men were reported to have a slightly higher rate of bile duct cancer than did the women, and our data support the previous finding and further demonstrate the pronounced association and influence of DM among the women in the context of ICC and ECC. The mechanisms through which the female sex plays a role in $\mathrm{CC}$ is believed to be related to the effect of hormone and its related receptors. Estrogen plays a crucial role in the pathogenesis of type 2 DM [28]. The estrogen level was higher in patients with CC [29]. Moreover, the estrogen level was increased in the serum of male patients with CC [30]. Two mechanisms through which estrogen or its receptor may play a direct or indirect role in the tumorigenesis of CC have been proposed. Estrogen acts on target tissues by binding to ESRs, ESR1 and ESR2, which have been detected in the tissues of the biliary tract [31-32]. Laboratory in vivo studies have indicated the presence of ESRs in the hepatobilary tree, including in bile duct epithelial cells, cholangiocytes, and $\mathrm{CC}$ cell lines [33-35], suggesting that estrogens play a role in $\mathrm{CC}$ carcinogenesis. Considering the potential hormonal role in biliary tract cancers, genetic variants in ESR1 and ESR2 genes have revealed an association between ESR

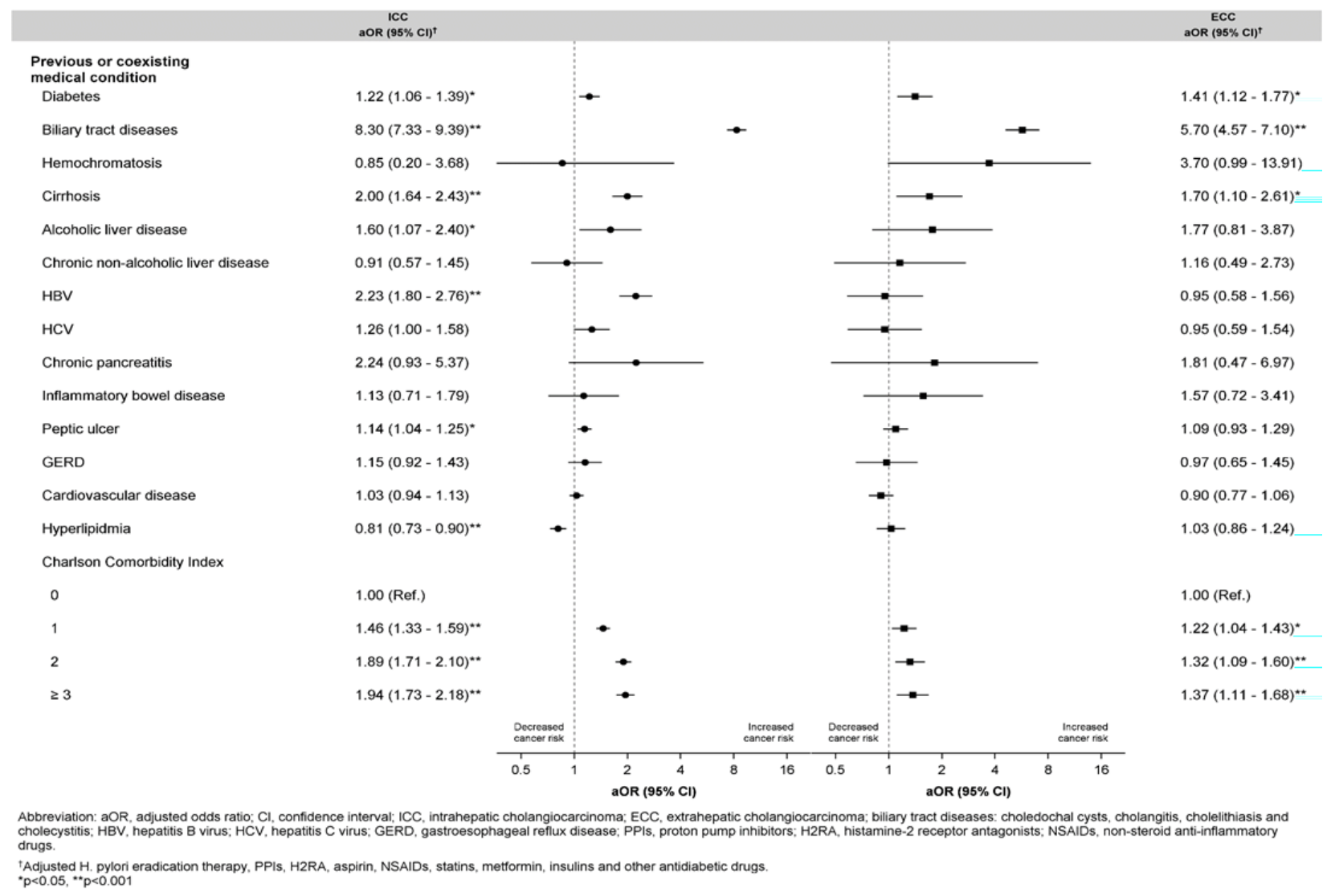

Figure 2: Adjusted Odd Ratios with 95\% Confidence Interval for Previous or Coexisting Conditions Associated with ICC or ECC. 
polymorphism [ESR1 rs1801132 (P325P)] and bile duct cancer, which was more pronounced among patients with a low BMI or without biliary stones through their effect on estrogenic activity [35-36]. Recent studies have reported that FXR, a nuclear receptor for bile acids, plays a critical role in bile acid homeostasis as well as in glucose and lipid metabolism. The function of FXR is related to CC [37-40]. FXR consists of two primary domains: the DNA binding domain and the ligand binding domain [39-40]. Extranuclear signaling can be conveyed to the specific DNA site through these functional domains. A study on CC and its potential molecular mechanisms reported that the imbalance in the ratio of free to conjugated bile acids may play a crucial role in the tumorigenesis of CC [41].

In vitro experiments confirmed the clinical data because activator chenodeoxycholic acid (CDCA) stimulated the proliferation of ER-positive cells only in a steroid-free medium; the stimulation inhibited the siRNAsilencing of the FXR expression as well as the ER blockade by antiestrogens [42]. Furthermore, an in vitro study on coimmunoprecipitation reported that CDCA activated-FXR interacted with ER [42]. In our study, compared with the controls, the risk of diabetes was more positively associated with ICC and ECC in the patients without biliary tract diseases. However, DM was not associated with the risk of ECC in the patients who received cholecystectomy. The pronounced association and influence of DM within the female sex in the context of ICC and ECC are likely to be related to a crosstalk between FXR and ER in female patients with ICC and ECC [42]. Although no FXR expression has been reported in bile ducts, studies have reported that bile salts can regulate secretory activities in human gallbladder epithelial cells [43-44]. Obese patients with diabetes may have impaired emptying of the gallbladder even in the absence of gallstones. Bile acids regulate metabolism by binding to the nuclear receptor FXR. If gallbladders where FXR is located are removed surgically, DM cannot result in the formation of bile stasis or gallstones within the gallbladder. In turn, the biliary tree inflammation produced as a result of surgery is likely to cause a physiological response while attempting to repair it through cholangiocyte proliferation, which is a risk factor for CC.

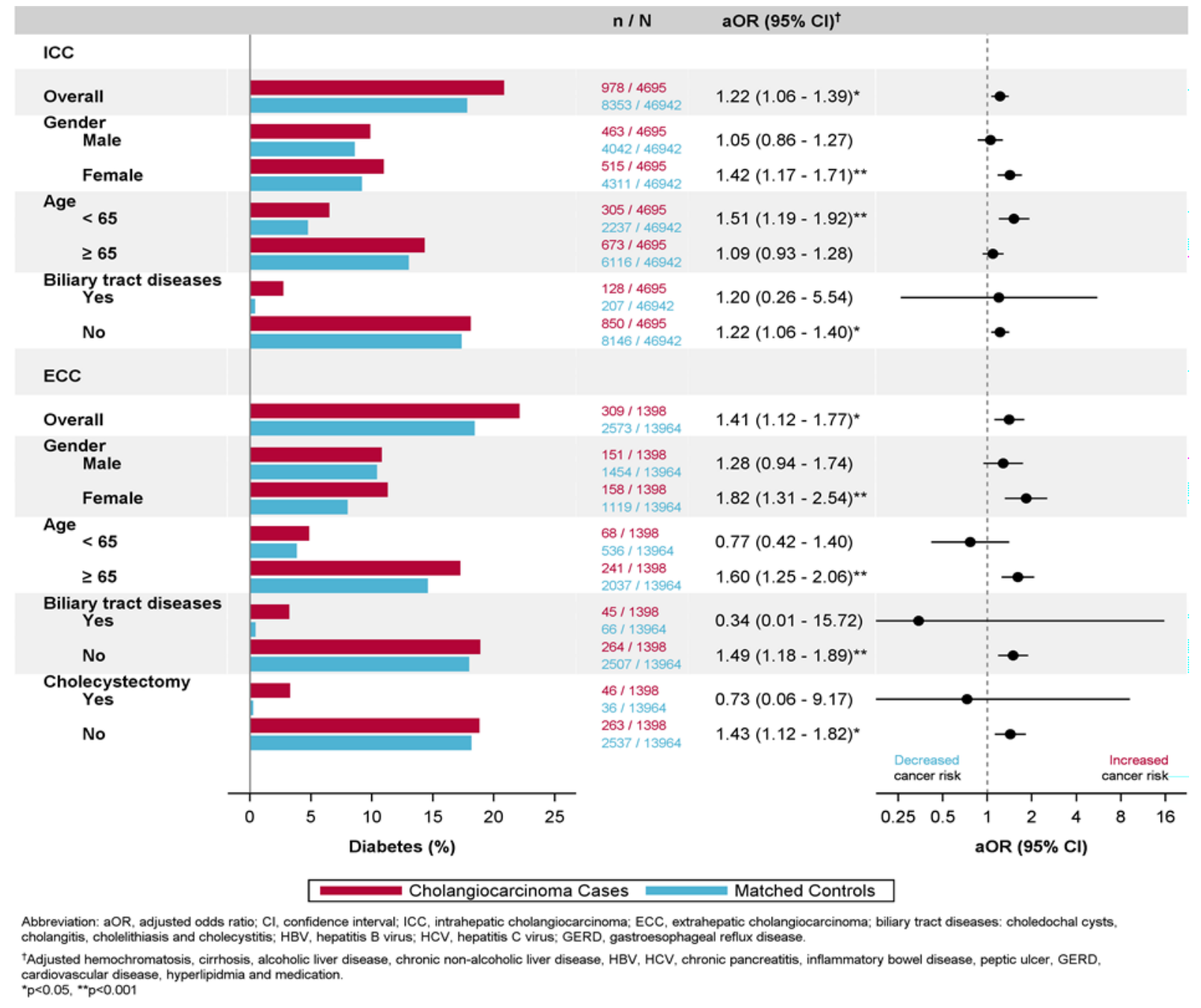

Figure 3: Subgroup-Specific Adjusted Odd Ratios With 95\% Confidence Interval for the Risk of Diabetes Associated with Increased Risk of ICC or ECC. 
Our results are partially in accordance with those of previous Asian studies that indicated a positive association between HBV and ICC [an adjusted OR of 2.23 (95\% CI: 1.80-2.76)] [45]. HCV was also identified to be associated with ICC, which is in contrast to the finding of a study that reported a strong association in Western populations but not in East-Asian populations [46].

This study has several limitations that should be addressed. First, the data sets used in this study did not have information on risk behaviors, such as smoking and alcohol consumption, severity of comorbidities, and indication for medication; therefore, we could only adjust the presence of disease and medication use. In addition, we only considered the presence of diseases that occurred in the diagnostic claims; however, the time from when a disease starts to when it is identified or diagnosed usually lags. The latency time window of disease diagnoses might induce confounding of the association with cancer incidence by failure to account for disease duration. Therefore, the results should be interpreted cautiously. Finally, this study was conducted in the Pacific-Asian region; thus, our results might not be generalizable to other populations.

\section{MATERIALS AND METHODS}

\section{Ethics statement}

This study was approved by the Joint Institutional Review Board of Taipei Medical University (approval no. 201503054). Confidentiality was ensured by abiding to the data regulations of the Health and Welfare Data Science Center (HWDC), Ministry of Health and Welfare, Executive Yuan, Taiwan. To protect privacy, the HWDC provides patient-level data to investigators for research purposes only and encrypts individual identifiers before releasing the data to researchers. Informed consent of participants was exempted under the full review process of the Joint Institutional Review Board of Taipei Medical University.

\section{Data source}

The Taiwan Cancer Registry (TCR), a populationbased cancer registry, collects data of patients with cancer by using the standardized procedures of the registry's reporting system. TCR was started in 1979, and hospitals with 50 beds and more were required to report the basic information of patients who received a new diagnosis of cancer. Following the enactment of the Cancer Control Act in 2003, all reporting hospitals were mandated to submit cancer data to TCR. The database has a 2-year time lag between collection and publication because of quality-control audits according to the standard guidelines of the International Agency for Research on Cancer.

The Taiwan National Health Insurance Research Database (NHIRD), which is maintained by the National Health Insurance Administration (NHIA), covers almost all reimbursement claims received by beneficiaries under the regulation of the National Health Insurance (NHI) program. Since 1995, all the citizens of Taiwan are required by law to enroll in the NHI, and the coverage rate was up to $99 \%$ in 2012 . The NHIRD contains patientlevel claims data including inpatient, outpatient, and prescription drugs for disease diagnoses and treatments. To verify the accuracy of diagnoses and rationale for treatments, the NHIA routinely audits a proportion of the NHI claims. The two data sets can be linked using unique patient identification numbers.

\section{Case and matched control selection}

From the TCR, we identified patients who received a diagnosis of CC between 2003 and 2009. Of these, we excluded patients who were aged less than 40 years, had received a diagnosis of other cancers in the observation period, were not continuously enrolled in the NHI since 2001, were foreign residents, or had unknown sex. Then, we classified patients into those with ICC and ECC on the basis of the International Classification of Disease of Oncology, Third Edition (ICD-O-3: C22.1 of ICC and C24.0 of ECC).

We selected up to 10 matched control patients without a history of cancer diagnosis during the study period from the study cohort. We used the incidence density sampling approach to match controls with each cancer case according to age ( \pm 1 year), sex, date of cohort entry, and date of last observation (case occurrence, censoring, or end of the study) [20]. This method reduced not only the potential bias in observational studies but also the time-window bias by differentiating exposure opportunity time windows between patients [21]. The date of cancer diagnosis was considered as the index date. All control patients were assigned a pseudo index date (referred as the index date hereafter), which corresponded to the index date of their matched cases.

\section{Risk factors}

DM was the major risk factor in this study. DM was defined if patients had two or more diagnostic claims of the International Classification of Disease, Ninth Revision, Clinical Modification (ICD-9-CM) code 250 in the NHIRD within 2 years prior to the index date. In addition, medication for treating patients with DM was also considered, including metformin, insulin, and other antidiabetic drugs based on their pharmacy claims. Patients were defined to have specific medication if they received a cumulative defined daily dose (cDDD) of more than 28 each year.

Other risk factors considered were biliary tract diseases (choledochal cysts, cholangitis, and cholelithiasis), cirrhosis, alcoholic liver disease, nonalcoholic liver disease, $\mathrm{HCV}, \mathrm{HBV}$, chronic pancreatitis, inflammatory bowel disease, peptic ulcer, gastroesophageal reflux disease, and cardiovascular diseases (atrial fibrillation, ischemic heart disease, congestive heart failure, and peripheral arterial disease) $[5,7]$. In addition, we used Charlson's comorbidity 
index (CCI) that is classified into four grades, $0,1,2$, and $\geq 3$, as a measure of homogeneity and severity of clinical conditions between cancer cases and matched controls. Other medications considered included proton pump inhibitors (PPIs), histamine-2 receptor antagonists ( $\left.\mathrm{H}_{2} \mathrm{RAs}\right)$, aspirin, nonsteroidal antiinflammatory drugs (NSAIDs), and statins. The same approach used for defining patients with DM was adopted for defining patients having a specific disease condition or receiving drug medication.

We particularly focused on Helicobacter pylori infection; however, the diagnosis of $H$. pylori infection was underreported in the NHIRD. Thus, we considered whether patients received $H$. pylori eradication therapy to evaluate its association with CC. In addition, we identified patients who received cholecystectomy (surgical removal of the gallbladder). Cholecystectomy is a common treatment for symptomatic gallstones and other gallbladder conditions. A study reported an association of gallstones with the risk of ECC and ICC. However, whether cholecystectomy reduces the risk of ECC remains unclear.

\section{Statistical analysis}

We investigated the association of the risk of DM with ECC and ICC by performing multivariate analyses with additional adjustments for potential confounders based on conditional logistic regression analyses. The odds ratios (ORs) and 95\% confidence intervals (CIs) were determined. In this nested case-control study using incidence density sampling, the calculated estimated incidence ratio was roughly equal to the OR because of the low incidence of CC [22]. All analyses were performed using SAS/STAT 9.2 software (SAS Institute Inc., Cary NC) and STATA 12 software (Stata Corp LP, College Station, TX). A P value of $<.05$ was considered significant.

\section{ACKNOWLEDGMENTS}

This study was supported by Health and Clinical Data Research Center, Taipei Medical University.

\section{CONFLICTS OF INTEREST}

All authors declare no conflicts of interests.

\section{REFERENCES}

1. International Diabetes Federation. IDF diabetes atlas, 6th ed. Brussels: International Diabetes Federation; c2014 [cited 2015 Aug 18]. Available from: http://www.idf. org/ sites/default/files/EN_6E_Atlas_Full_0.pdf.

2. Yang W, Lu J, Weng J, Jia W, Ji L, Xiao J, Shan Z, Liu J, Tian H, Ji Q et al. Prevalence of diabetes among men and women in China. The New England journal of medicine. 2010, 362:1090-1101.
3. Welzel TM, Mellemkjaer L, Gloria G, Sakoda LC, Hsing AW, El Ghormli L, Olsen JH, McGlynn KA. Risk factors for intrahepatic cholangiocarcinoma in a low-risk population: a nationwide case-control study. International journal of cancer. 2007, 120:638-641

4. Chen YK, Yeh JH, Lin CL, Peng CL, Sung FC, Hwang IM, $\mathrm{Kao} \mathrm{CH}$. Cancer risk in patients with cholelithiasis and after cholecystectomy: a nationwide cohort study. Journal of gastroenterology. 2014, 49:923-931.

5. Nordenstedt H, Mattsson F, El-Serag H, Lagergren J. Gallstones and cholecystectomy in relation to risk of intraand extrahepatic cholangiocarcinoma. British journal of cancer. 2012, 106:1011-1015.

6. Tsai MS, Lin WH, Hsu WM, Lai HS, Lee PH, Chen WJ. Clinicopathological feature and surgical outcome of choledochal cyst in different age groups: the implication of surgical timing. Journal of gastrointestinal surgery. 2008, 12:2191-2195.

7. Welzel TM, Graubard BI, El-Serag HB, Shaib YH, Hsing AW, Davila JA, McGlynn KA. Risk factors for intrahepatic and extrahepatic cholangiocarcinoma in the United States: a population-based case-control study. Clinical gastroenterology and hepatology. 2007, 5:1221-1228.

8. Nakeeb A, Pitt HA, Sohn TA, Coleman J, Abrams RA, Piantadosi S, Hruban RH, Lillemoe KD, Yeo CJ, Cameron JL. Cholangiocarcinoma. A spectrum of intrahepatic, perihilar, and distal tumors. Annals of surgery. 1996, 224:463-473; discussion 473-465.

9. Esposito I, Schirmacher P. Pathological aspects of cholangiocarcinoma. HPB. 2008, 10:83-86.

10. Khan SA, Davidson BR, Goldin RD, Heaton N, Karani J, Pereira SP, Rosenberg WM, Tait P, Taylor-Robinson SD, Thillainayagam AV et al. Guidelines for the diagnosis and treatment of cholangiocarcinoma: an update. Gut. 2012, 61:1657-1669.

11. Chang JS, Tsai CR, Chen LT. Medical risk factors associated with cholangiocarcinoma in Taiwan: a population-based case-control study. PloS one. 2013, 8:e69981.

12. Grainge MJ, West J, Solaymani-Dodaran M, Aithal GP, Card TR. The antecedents of biliary cancer: a primary care case-control study in the United Kingdom. British journal of cancer. 2009, 100:178-180.

13. Shaib YH, El-Serag HB, Davila JA, Morgan R, McGlynn KA. Risk factors of intrahepatic cholangiocarcinoma in the United States: a case-control study. Gastroenterology. 2005, 128:620-626.

14. Lee TY, Lee SS, Jung SW, Jeon SH, Yun SC, Oh HC, Kwon S, Lee SK, Seo DW, Kim MH et al. Hepatitis B virus infection and intrahepatic cholangiocarcinoma in Korea: a case-control study. The American journal of gastroenterology. 2008, 103:1716-1720.

15. Zhou YM, Yin ZF, Yang JM, Li B, Shao WY, Xu F, Wang YL, Li DQ. Risk factors for intrahepatic 
cholangiocarcinoma: a case-control study in China. World journal of gastroenterology. 2008, 14:632-635.

16. Patel T. Increasing incidence and mortality of primary intrahepatic cholangiocarcinoma in the United States. Hepatology (Baltimore, Md). 2001, 33:1353-1357.

17. Nathan H, Pawlik TM, Wolfgang CL, Choti MA, Cameron JL, Schulick RD. Trends in survival after surgery for cholangiocarcinoma: a 30-year population-based SEER database analysis. Journal of gastrointestinal surgery. 2007, 11:1488-1496; discussion 1496-1487.

18. Chien LN, Huang YJ, Shao YH, Chang CJ, Chuang MT, Chiou HY, Yen Y. Proton pump inhibitors and risk of periampullary cancers-A nested case-control study. International journal of cancer. 2016, 138:1401-1409.

19. Jianu CS, Lange OJ, Viset T, Qvigstad G, Martinsen TC, Fougner R, Kleveland PM, Fossmark R, Hauso O, Waldum HL. Gastric neuroendocrine carcinoma after long-term use of proton pump inhibitor. Scandinavian journal of gastroenterology. 2012, 47:64-67.

20. Bernstein H, Bernstein C, Payne CM, Dvorakova $\mathrm{K}$, Garewal H. Bile acids as carcinogens in human gastrointestinal cancers. Mutation research. 2005, 589:47-65.

21. Payne CM, Bernstein C, Dvorak K, Bernstein $\mathrm{H}$. Hydrophobic bile acids, genomic instability, Darwinian selection, and colon carcinogenesis. Clinical and experimental gastroenterology. 2008, 1:19-47.

22. Rotman SR, Bishop TF. Proton pump inhibitor use in the U.S. ambulatory setting, 2002-2009. PloS one. 2013, 8:e56060.

23. Chung SC, Leung JW, Li AK. Bile duct size after cholecystectomy: an endoscopic retrograde cholangiopancreatographic study. The British journal of surgery. 1990, 77:534-535.

24. Hsing, A.W. et al. Biliary tract cancer. In Schottenfeld, D. and Fraumeni, J.F. (eds.) Cancer Epidemiology and Prevention. Oxford University Press, New York, NY, pp. 787-800. (2006).

25. Khan ZR, Neugut AI, Ahsan H, Chabot JA. Risk factors for biliary tract cancers. The American journal of gastroenterology. 1999, 94:149-152.

26. Morita T, Tabata S, Mineshita M, Mizoue T, Moore MA, Kono S. The metabolic syndrome is associated with increased risk of colorectal adenoma development: the SelfDefense Forces health study. Asian Pacific journal of cancer prevention. 2005, 6:485-489.

27. Tai TY, Chuang LM, Tsai ST, Huang BY. Treatment of type 2 diabetes mellitus in a primary care setting in Taiwan: comparison with secondary/tertiary care. Journal of the Formosan Medical Association. 2006, 105:105-117.

28. Motawi TM, El-Rehany MA, Rizk SM, Ramzy MM, El-Roby DM. Genetic polymorphism of estrogen receptor alpha gene in Egyptian women with type II diabetes mellitus. Meta gene. 2015, 6:36-41.
29. Kuper H, Lagiou P, Mucci LA, Tamimi R, Benetou V, Trichopoulos D. Risk factors for cholangiocarcinoma in a low risk Caucasian population. Sozial- und Praventivmedizin. 2001, 46:182-185.

30. Hunsawong $T$, Singsuksawat E, In-chon $\mathrm{N}$, Chawengrattanachot W, Thuwajit C, Sripa B, Paupairoj A, Chau-in S, Thuwajit P. Estrogen is increased in male cholangiocarcinoma patients' serum and stimulates invasion in cholangiocarcinoma cell lines in vitro. Journal of cancer research and clinical oncology. 2012, 138:1311-1320.

31. Curtis Hewitt S, Couse JF, Korach KS. Estrogen receptor transcription and transactivation: Estrogen receptor knockout mice: what their phenotypes reveal about mechanisms of estrogen action. Breast cancer research. 2000, 2:345-352

32. Nakamura S, Muro H, Suzuki S. Estrogen and progesterone receptors in gallbladder cancer. The Japanese journal of surgery. 1989, 19:189-194

33. Alvaro D, Alpini G, Onori P, Perego L, Svegliata Baroni G, Franchitto A, Baiocchi L, Glaser SS, Le Sage G, Folli F et al. Estrogens stimulate proliferation of intrahepatic biliary epithelium in rats. Gastroenterology. 2000, 119:1681-1691.

34. Alvaro D, Alpini G, Onori P, Franchitto A, Glaser SS, Le Sage G, Folli F, Attili AF, Gaudio E. Alfa and beta estrogen receptors and the biliary tree. Molecular and cellular endocrinology. 2002, 193(1-2):105-108.

35. Fumino S, Iwai N, Deguchi E, Kimura O, Ono S, Iwabuchi $\mathrm{T}$. Estrogen receptor expression in anomalous arrangement of the pancreaticobiliary duct. Journal of pediatric surgery. 2005, 40:1716-1720.

36. Park SK, Andreotti G, Rashid A, Chen J, Rosenberg PS, Yu K, Olsen J, Gao YT, Deng J, Sakoda LC et al. Polymorphisms of estrogen receptors and risk of biliary tract cancers and gallstones: a population-based study in Shanghai, China. Carcinogenesis. 2010, 31:842-846.

37. Wang H, Chen J, Hollister K, Sowers LC, Forman BM. Endogenous bile acids are ligands for the nuclear receptor FXR/BAR. Molecular cell. 1999, 3:543-553.

38. Kim I, Ahn SH, Inagaki T, Choi M, Ito S, Guo GL, Kliewer SA, Gonzalez FJ. Differential regulation of bile acid homeostasis by the farnesoid $\mathrm{X}$ receptor in liver and intestine. Journal of lipid research. 2007, 48:2664-2672.

39. Zhang Y, Lee FY, Barrera G, Lee H, Vales C, Gonzalez FJ, Willson TM, Edwards PA. Activation of the nuclear receptor FXR improves hyperglycemia and hyperlipidemia in diabetic mice. Proceedings of the National Academy of Sciences of the United States of America. 2006, 103:1006-1011.

40. Trauner M. The nuclear bile acid receptor FXR as a novel therapeutic target in cholestatic liver diseases: hype or hope? Hepatology (Baltimore, Md). 2004, 40:260-263.

41. Dai J, Wang H, Shi Y, Dong Y, Zhang Y, Wang J. Impact of bile acids on the growth of human cholangiocarcinoma via FXR. Journal of hematology \& oncology. 2011, 4:41. 
42. Journe F, Durbecq V, Chaboteaux C, Rouas G, Laurent G, Nonclercq D, Sotiriou C, Body JJ, Larsimont D. Association between farnesoid $\mathrm{X}$ receptor expression and cell proliferation in estrogen receptor-positive luminal-like breast cancer from postmenopausal patients. Breast cancer research and treatment. 2009, 115:523-535.

43. Chignard N, Mergey M, Veissiere D, Parc R, Capeau J, Poupon R, Paul A, Housset C. Bile acid transport and regulating functions in the human biliary epithelium. Hepatology (Baltimore, Md). 2001, 33:496-503.

44. Chignard N, Mergey M, Veissiere D, Poupon R, Capeau J, Parc R, Paul A, Housset C. Bile salts potentiate adenylyl cyclase activity and cAMP-regulated secretion in human gallbladder epithelium. American journal of physiology Gastrointestinal and liver physiology. 2003, 284: G205-212.

45. Lee TY, Lee SS, Jung SW, Jeon SH, Yun SC, Oh HC, Kwon S, Lee SK, Seo DW, Kim MH, Suh DJ. Hepatitis $\mathrm{B}$ virus infection and intrahepatic cholangiocarcinoma in Korea: a case-control study. Am J Gastroenterol. 2008; 103 : 1716-1720.

46. Palmer WC, Patel T. Are common factors involved in the pathogenesis of primary liver cancers? A meta-analysis of risk factors for intrahepatic cholangiocarcinoma. J Hepatol. 2012; 57:69-76. 